\title{
Where Would We Be Without Counterfactuals?*
}

\author{
Huw Price
}

\begin{abstract}
Bertrand Russell's celebrated essay "On the Notion of Cause" was first delivered to the Aristotelian Society on 4 November 1912, as Russell's Presidential Address. The piece is best known for a passage in which its author deftly positions himself between the traditional metaphysics of causation and the British crown, firing broadsides in both directions: "The law of causality", Russell declares, "Like much that passes muster in philosophy, is a relic of a bygone age, surviving, like the monarchy, only because it is erroneously supposed to do no harm." To mark the lecture's centenary, I offer a contemporary view of the issues Russell here puts on the table, and of the health or otherwise, at the end of the essay's first century, of his notorious conclusion.
\end{abstract}

\section{Remembering Russell}

One hundred years ago, ${ }^{1}$ on 4 November 1912 , Bertrand Russell delivered the Inaugural Address to the Aristotelian Society's thirty-fourth session - it was Russell's second year as President. His lecture was entitled "On the Notion of Cause", and the Society's Proceedings inform us that a discussion followed in which a number of members took part. Outside the Aristotelian Society, the discussion continues to this day. Russell's paper remains both influential and controversial. It is widely known as the source of one of the most famous lines in twentieth century philosophy: "The law of causation", Russell declares, "Like much that passes muster among philosophers, is a relic of a bygone age, surviving, like the monarchy, only because it is erroneously supposed to do no harm." (Russell 1913, p. 1)

As it happens, "On the Notion of Cause" is the one piece of Russell's entire philosophical output with which my own work connects directly - certainly the only one where I make any claim to advancing the matters under discussion. So I want to take advantage of this happy coincidence to use my own inaugural lecture, to the Cambridge professorship that now bears Russell's name, to celebrate the

\footnotetext{
${ }^{*}$ To appear in Galavotti, M. C., Dieks, D., Gonzalez, W., Hartmann, S., Uebel, T., and Weber, W., eds, New Directions in the Philosophy of Science, Springer, 2014.

${ }^{1}$ This piece was written for delivery on 1 November 2012, as my inaugural lecture as the Bertrand Russell Professor of Philosophy, Cambridge. I am very grateful to Maria Carla Galavotti and the organisers of the conference "New Directions in Philosophy of Science" for the invitation that enabled me to give the lecture as a dress rehearsal in Bertinoro on 20 October 2012, and to the audience on that occasion for many helpful comments and questions.
} 
centenary of this famous paper; and to say something about what its conclusions look like, at least from my perspective, with the benefit of a century's hindsight.

It is a story with a lot of Cambridge connections. Indeed, I'm not the first occupant of what is now the Bertrand Russell Chair to mention Russell's paper in an inaugural lecture. Anscombe does so in her lecture "Causality and Determination", from 1971:

"Russell wrote of the notion of cause, or at any rate of the "law of causation' (and he seemed to feel the same way about 'cause' itself), that, like the British monarchy, it had been allowed to survive because it had been erroneously thought to do no harm. In a destructive essay of great brilliance he cast doubt on the notion of necessity involved, unless it is explained in terms of universality, and he argued that upon examination the concepts of determination and of invariable succession of like objects upon like turn out to be empty: they do not differentiate between any conceivable course of things and any other." (Anscombe 1971, p. 135)

This brings Anscombe to her own concern, namely, indeterministic conceptions of causality, and it gives her a reason to take Russell to task: "Thus Russell too assumes that necessity or universality is what is in question, and it never occurs to him that there may be any other conception of causality." (ibidem)

My concerns are different from Anscombe's, but I will follow her in one respect, interpreting Russell's target broadly rather than narrowly. Anscombe takes it to include "cause", as well as "the law of causation". I'm going to take it to include a broad class of counterfactual judgements - judgements of the form "If A had not happened, the B would not have happened." I don't suggest that Russell himself took his thesis to extend this far; but the history of the subject since Russell's time has shown that such counterfactuals are closely connected not only to causation in general, but to some of the specific issues about causation at the core of Russell's paper.

One of Russell's key arguments concerns the time-asymmetry of causation - the fact that effects are supposed to occur later than their causes (or at least not earlier than their causes). Russell says that there is nothing to ground such a difference between past and future in fundamental physics. More recent writers have noted that there is a similar time-asymmetry in counterfactual reasoning. If the lights had failed at the beginning of this lecture, the proceedings since that moment might well have been different - I would not have progressed this far, for example - but events before the failure of the lights would have just the same; or at least, so our intuitions tell us. David Lewis (1989) calls this the asymmetry of counterfactual dependence, and proposes to use it to explain the asymmetry of causation, that Russell had taken to be missing in fundamental physics.

A good question at this point is where the time-asymmetry of counterfactual dependence comes from, if Russell is right, and there isn't anything suitable in fundamental physics? I'll come back to this. For the moment, I've mentioned it to 
make the point that we can't sensibly discuss the issues raised by Russell's paper without broadening the scope in this way, to include counterfactuals.

But broadening the scope raises the stakes. Russell seems to be suggesting that abandoning talk of causality would be practical, as well as desirable, much as abandoning the monarchy might be: some planning, a few days of mild confusion, and it would all be done. Indeed, he thought that modern physicists, vanguards of the revolution, had already made the change:

"All philosophers, of every school, imagine that causation is one of the fundamental axioms or postulates of science, yet, oddly enough, in advanced sciences such as gravitational astronomy, the word 'cause' never occurs." (ibidem)

Russell then singles out for criticism his former teacher, James Ward, who was actually the very first holder of this chair - its inaugural inauguree, so to speak. Russell says that Ward makes the fact that the advanced sciences don't mention causation "a ground for complaint against physics: the business of science, he apparently thinks, should be the discovery of causes, yet physics never even seeks them." Russell replies: "To me it seems that philosophy ought not to assume such legislative functions, and that the reason why physics has ceased to look for causes is that, in fact, there are no such things." (ibidem) (After that, we get the famous line about monarchy.)

Now, it is debatable whether Russell was right even about physics - or whether, even if he was right about the advanced physics of his own time, what he saw was actually a general feature of future (presumably even more advanced) physics. Forty years ago, Patrick Suppes argued that Russell's claim was not true of the physics of the 1960s.

"Contrary to the days when Russell wrote this essay, the words 'causality' and 'cause' are commonly and widely used by physicists in their most recent work. There is scarcely an issue of Physical Review that does not contain at least one article using either 'cause' or 'causality' in its title." (Suppes 1970, pp. 5-6)

But even if Russell is right about physics, the idea that we could dispense with talk of causality much as we might dispense with the monarchy still seems wildly unrealistic.

The point is even more obvious when we notice the way in which counterfactuals are liable to be swept up in the same net. For my text at this point I take some wise words I once heard attributed to the distinguished American philosopher, Jerry Fodor. "Why is real estate in Manhattan so damned expensive?", Fodor asks - "You're paying for all those counterfactuals!" As usual from Fodor, it's a pithy little piece of philosophy, served with a generous amuse bouche. And he's right, to a considerable extent, obviously.

But imagine the consequences if Fodor's news and Russell's news leak out at the same time. The value of your apartment depends on its counterfactuals, 
but Bertrand Russell says there ain't no counterfactuals! So the whole Manhattan market is a gigantic Ponzi scheme, built not on sand, not even on paper, but literally on nothing! It's unthinkable - and literally so, perhaps, if counterfactual thought is to be imagined groundless, and yet we need a counterfactual to ask the question, as in my title.

At this point we might defend Russell by suggesting that his real target is much more modest. His view about the the word "cause", as he puts it, is that it "is so inextricably bound up with misleading associations as to make its complete extrusion from the philosophical vocabulary desirable" (ibidem, my emphasis), and that there are no causes at a fundamental level in physics. But this is compatible, perhaps, with recognising a non-fundamental role for causal vocabulary (and counterfactuals too), in non-fundamental parts of physics and in everyday life. Provided such a role could be found, then we might save the real estate market, indeed the finance system itself - for what is money except a convenient form of exchangeable counterfactuals? - without treating talk of causation and counterfactuals as tracking some deep, God-given feature of the furniture of reality. (After all, remember the first three laws of real estate - "Location, location, location". They surely survive the discovery that there is no such thing as absolute space!)

So we can defend Russell by taking him, like Hume before him perhaps, to be proposing only an armchair revolution. He wants to banish "causation" from the kind of serious conversation that goes on around the Great Court at Trinity College (and similarly venues elsewhere, if such there be), without banishing it from the streets. (Where contemporary physics falls under this regime would be a matter for debate. We would need to figure out what physicists mean when they talk of causation, and that might be a lengthy investigation.)

But even this modest armchair revolution seems to be undone by a famous paper by Nancy Cartwright, her "Causal Laws and Effective Strategies" (Cartwright 1979). Cartwright begins with Russell's distinction between symmetric laws of association - the kind of Humean regularities Russell thinks that modern physics actually offers us - and the asymmetric causal laws Russell thinks we need to dispense with (at least in the armchair). She notes that Russell argues for two conclusions: in her words, (i) that "laws of association are all the laws there are", and (ii) "that causal principles cannot be derived from the causally symmetric laws of association". She goes on to argue "in support of Russell's second claim, but against the first." (1979, p. 419) That is, she agrees that "[c]ausal principles cannot be reduced to laws of association", but maintains that "they cannot be done away with." (ibidem)

Cartwright's argument is that causal laws are needed to ground an an important distinction between effective and ineffective strategies. She illustrates this distinction with some examples, one of them a letter she tells us she received from an insurance company, making the following claim:

“It simply wouldn't be true to say, 'Nancy L. D. Cartwright ... if you own a TIAA life insurance policy, you'll live longer.' But it is a fact, 
nonetheless, that persons insured by TIAA do enjoy longer lifetimes, on the average, than persons insured by commercial insurance companies that serve the general public." (1979, p. 420)

Cartwright argues that the objective fact reported in this letter - viz., that buying life insurance from this company would not be an effective strategy for living longer - depends on causal rather than merely probabilistic facts about the world. But, she argues, the "objectivity of strategies requires the objectivity of causal laws". In other words, she concludes,

"causal laws cannot be done away with, for they are needed to ground the distinction between effective strategies and ineffective ones. ... [T] he difference between the two depends on the causal laws of our universe, and on nothing weaker." (ibidem)

Commenting on Cartwright's argument in a recent survey paper, Hartry Field concludes:

"This makes a compelling case against Russell's view that we should do without causal notions. But Cartwright herself draws a much stronger conclusion, a kind of causal hyper-realism, according to which there are causal facts that outrun the totality of 'noncausal facts' (i.e. the facts that could be expressible in some language without using causal terminology). Indeed, her claim isn't simply that there is no reasonable way to explicitly define causation in noncausal terms; it seems to be that causal claims don't even supervene on the noncausal facts. Among the 'noncausal facts' she includes the basic laws of physicse.g. Newton's law that an object accelerates in direct proportion to the force impressed on it and in inverse proportion to its mass. She holds that the causal fact that a force on an object makes the object go faster is not reducible to Newton's law, nor to other noncausal facts either, such as the equations of energy flow from the sources of fields to the fields themselves to the accelerating objects. (Such equations are just further parts of fundamental physics, which she regards as 'laws of association' rather than as causal.) Rather, the claim that a force on an object makes the object go faster states a further truth about the world that physics leaves out. Evidently there is some sort of causal fluid that is not taken account of in the equations of physics; just how it is that we are supposed to have access to its properties I am not sure." (Field 2003, §2)

Field finds this hyper-realism unpalatable, but recognises the importance of Cartwright's challenge:

"But despite the implausibility of the hyper-realist picture, we have a problem to solve: the problem of reconciling Cartwright's points about 
the need of causation in a theory of effective strategy with Russell's points about the limited role of causation in physics. This is probably the central problem in the metaphysics of causation." (ibidem, $\S 2$, emphasis added)

For my part, I agree with Field, except that I think it would be better to say that it is one of two central problems, the other being Russell's issue of the timeasymmetry of causation. Accounting for that is a further difficulty for the hyperrealist view, but it is a problem for all views, including views which want to regard causation as something relatively non-fundamental. ${ }^{2}$

\section{Russell on time-asymmetry}

Russell's own treatment of the problem of the apparent time-asymmetry of causation is important more because he sees that there is a problem than because he provides any satisfactory solution, or dissolution. Let's have a look at the central passage. Russell puts his cards on the table straightaway:

"We all regard the past as determined simply by the fact that it has happened; but for the accident that memory works backward and not forward, we should regard the future as equally determined by the fact that it will happen." (Russell 1913, pp. 20-21)

In other words, so Russell is claiming, there's no real distinction between past and future, but an accident about us - the fact that memory works backwards not forwards - tricks us into thinking that there is. He then counters his own claim with a plausible objection: “'But,' we are told, 'you cannot alter the past, while you can to some extent alter the future." (ibidem)

In reply to this Russell makes two points. The first that while it is true that "you cannot make the past other than it was", this is just a matter of logic, and the same is true with respect to the future. The second - acknowledging, I think, that the first has not got to the heart of the matter - introduces what turns out be an important link between what we think we can influence and what we can know:

"[I]f you happen to know the future-e.g., in the case of a forthcoming eclipse-it is just as useless to wish it different as to wish the past different." (ibidem)

Russell's self-scripted interlocutor now does a good job of getting things back on track:

\footnotetext{
${ }^{2}$ This problem has also been much discussed in recent literature, especially by way of criticism of David Lewis's attempt, mentioned above, to explain a corresponding asymmetry of counterfactual dependence, to which that of causation might then be reduced. See, e.g., Price and Weslake (2009) and references therein.
} 
“'But,' it will be rejoined, 'our wishes can cause the future, sometimes, to be different from what it would be if they did not exist, and they can have no such effect upon the past."” (ibidem)

(Even though we often don't know the past, if would have been helpful to add!)

At this point, I think, Russell loses his grip on the force of his opponent's argument. What he says is just this:

"This, again, is a mere tautology. An effect being defined as something subsequent to its cause, obviously we can have no effect upon the past." (ibidem)

But we can just give Russell the terms "cause" and "effect", defined in this way, and press the original objection as the question as to why it never makes sense to act for (or "wish for") ends which - while not effects of our actions (being ruled out as such by this definition, because they lie in the past) - are nevertheless desirable, from our point of view. Why is it useless to do something now to ensure that my ticket was the winning ticket in a lottery drawn yesterday, for example (if I don't yet know that it is not)? Call this the problem of the time-asymmetry of deliberation. Russell doesn't get this problem in focus, I think. You can't avoid the question by saying that an end for which we act is by definition an effect of our action, because then you'd have two definitions of "effect" in play, and you'd need to explain why they line up - and that's just the original problem.

There then follows an interesting little passage I won't go into in detail, in which Russell is in effect denying what we now call the asymmetry of counterfactual dependence:

"But that does not mean that the past would not have been different if our present wishes had been different. Obviously, our present wishes are conditioned by the past, and therefore could not have been different unless the past had been different; therefore, if our present wishes were different, the past would be different. Of course, the past cannot be different from what it was, but no more can our present wishes be different from what they are; this again is merely the law of contradiction." (ibidem)

And Russell then sums up:

"The facts seem to be merely (1) that wishing generally depends upon ignorance, and is therefore commoner in regard to the future than in regard to the past, (2) that where a wish concerns the future, it and its realization very often form a 'practically independent system,' i.e., many wishes regarding the future are realized. But there seems no doubt that the main difference in our feelings arises from the fact that the past but not the future can be known by memory." (ibidem)

I want to emphasise three points: 
1. Russell is trying to explain the apparent time-asymmetry of causal dependence as a product of a difference in us, rather than a fundamental difference in reality. (As I'll explain, I think he's right about that.)

2. The difference he picks concerns memory, but it's doubtful whether that can do the trick - it doesn't draw a clean enough cut between past and future, because we remember rather little of the past, and know some of the future by other means.

3. He already has on the table the idea that the business of realization of our wishes, as he quaintly puts it, is important in explaining the illusion of asymmetry - though, hampered by the thought that it is all about memory, he doesn't get very far.

And that positions us for the next step in this story, which belongs to perhaps the greatest of all these early twentieth century Cambridge giants, Frank Ramsey.

\section{Ramsey's special agent}

The step in question occurs in Ramsey's very late paper, "General Propositions and Causality", a rough thirty-page manuscript dated September 1929 (just four months before Ramsey's tragically early death, at the age of 26). About two-thirds of the way through, Ramsey turns to the issues of the difference between past and future and the direction of causality. Then, in a few short paragraphs - little more than two handwritten pages - he dissects his way to core of the problem, and shows us what he takes to lie at its heart. In my view, this is one of the most insightful passages not merely in twentieth century philosophy, but in all of philosophy. Indeed, given the centrality of the issues at stake here - causality, the direction of time, and the location, in these respects, of the cut between what properly belongs in the world, and what it some sense "stems from us" - I think it has some claim to be a significant landmark in human thought as a whole.

As usual, however, Ramsey is here "too brisk for most philosophers," as Hugh Mellor (1988, p. 254) said of a different piece of Ramsey, in his own inaugural lecture to this chair. And unusually, I think, he doesn't quite get everything right what survives of his view is just the back of the envelope version, after all. But he does give us an answer to both the puzzles we have on the table. I'll give you the core of the relevant passage, highlighting what I take to be some key remarks, and then explain these points in more detail.

"It is, it seems, a fundamental fact that the future is due to the present, or, more mildly, is affected by the present, but the past is not. What does this mean? It is not clear and, if we try to make it clear, it turns into nonsense or a definition...

[W]e think there is some difference between before and after at which we are getting; but what can it be? There are differences between 
the laws deriving effect from cause and those deriving cause from effect; but can they really be what we mean? No; for they are found $a$ posteriori, but what we mean is a priori. [The Second Law of Thermodynamics is a posteriori; what is peculiar is that it seems to result merely from absence of law (i.e. chance), but there might be a law of shuffling.]

What then do we believe about the future that we do not believe about the past; the past, we think, is settled; if this means more than that it is past, it might mean that it is settled for us, that nothing now could change our opinion of it, that any present event is irrelevant to the probability for us of any past event. But that is plainly untrue. What is true is this, that any possible present action ${ }^{3}$ volition of ours is (for us) irrelevant to any past event. To another (or to ourselves in the future) it can serve as a sign of the past, but to us now what we do affects only the probability of the future.

This seems to me the root of the matter; that I cannot affect the past, is a way of saying something quite clearly true about my degrees of belief. Again from the situation when we are deliberating seems to me to arise the general difference of cause and effect. We are then engaged not on disinterested knowledge or classification (to which this difference is utterly foreign), but on tracing the different consequences of our possible actions, which we naturally do in sequence forward in time, proceeding from cause to effect not from effect to cause. We can produce $\mathrm{A}$ or $\mathrm{A}^{\prime}$ which produces $\mathrm{B}$ or $\mathrm{B}^{\prime}$ which etc. ...; the probabilities of A, B are mutually dependent, but we come to A first from our present volition. ... In a sense my present action is an ultimate and the only ultimate contingency." (Ramsey 1929, pp. 145-46, emphasis in bold added)

These are some of the ideas we find in this extraordinary passage:

\subsection{Agency is the key to understanding causation}

Ramsey thinks that causation - especially the asymmetry of causation, the difference between cause and effect - needs to be understood by thinking about "the situation when we are deliberating." This idea turns up in later writers, including at least three with Cambridge connections. The first of these was Douglas Gasking, a student in Cambridge the 1930s, and later a lecturer at the University of Melbourne, who defends the idea in a wonderful paper in Mind in 1955 (Gasking 1955); the second was G. H. von Wright, briefly Wittgenstein's successor in this chair, who defended such a view in the 1970s (von Wright 1973, 1975). In Oxford, Collingwood (1940) had proposed it in the 1930s. But so far as I know, none of

\footnotetext{
${ }^{3}$ This deletion is present in the manuscript of Ramsey's paper.
} 
these writers recognised that Ramsey was on to the idea, nor gets anywhere close to the insights that connect Ramsey's version of the view to the issues raised by Russell's paper.

Later, in the early 1990s, I also defended a version of this agency view, both in joint work with my Australian colleague Peter Menzies (Menzies and Price 1993) and elsewhere (Price 1991, 1993). This time Ramsey does get a mention, as do issues such as the time-asymmetry of causation, and Cartwright's challenge to Russell. More recently still, the idea that causation needs to be understood in terms of "manipulation", as people now say, has been very prominent over the past decade or so, thanks to the work of the philosopher Jim Woodward (2003) and the computer scientist Judea Pearl (2000), amongst others. But Ramsey was the first, so far as I know.

\subsection{Probability looks different from an agent's point of view}

Ramsey's key insight is that agents are epistemically "special" - probability judgements are properly different from an agent's first-person point of view, than from a third-person point of view (even that of the same agent at other times). Ramsey puts this initially as the claim that our own present volitions are, for us, probabilistically independent of "any past event". He doesn't actually tell us why this is so, though he does give us a hint at the end: "my present action is an ultimate and the only ultimate contingency".

What he has in mind, I think, is a generalisation of what is now a familiar point about how knowledge and free choice conflict. It doesn't make sense to take yourself to be choosing between options one of which you know to obtain. (Remember Russell's example of the eclipse, known in advance.) The point emerges in the oddity of saying something like, "I know I'll vote for Obama, but I'm still making up my mind." You take away with one hand the authority you bestow with the other, much as in Moore's paradox, when you say "P, but I don't believe that P."

Ramsey generalises this point from knowledge to credence, so that it becomes the claim that an agent cannot take herself to have evidence about what she is going to do, as she deliberates. ("Deliberation screens prediction", as Rabinowicz (2002) puts it.) From the agent's point of view, her contemplated action must be regarded as probabilistically independent of anything she does she know at present - even if other people (or she herself at other times) could legitimately take something of that kind as evidence about her choice, or vice versa.

In my view, this is the key to solving Field's puzzle. The differences Cartwright rightly points to between the probabilities we get from laws of association, on the one hand, and the probabilities associated with what we take to be causal dependencies, on the other, are precisely the differences induced by the specialness of agency. Cartwright is right in thinking that we can't explain effective strategy in terms of the former; but wrong to think that we need causal laws to give us the latter. On the contrary, as I think Ramsey first saw, it's the other way round: the specialness of the agent's perspective grounds our talk of causation. 


\subsection{The time-asymmetry of causation}

This leaves the problem of the time-asymmetry of causation, and here I think Ramsey is at least looking in the right direction, saying it depends "on tracing the different consequences of our possible actions, which we naturally do in sequence forward in time." The first comment we need to make here is that "consequences" must mean something like "probabilistic dependencies", if Ramsey is not to be accused of slipping in talk of causation at this point. Second, since Ramsey has already appealed to the idea that there are no such dependencies between our present actions and events in the past, the qualification "naturally" is in a sense unneeded: if Ramsey is right, there are no dependencies except "forward in time." (Imagine turtles hatched on an East-facing beach. Is it any surprise that their journey takes them asymmetrically to the East? No, for there are no routes to the West, from their point of view.)

Still, the term "naturally" is useful in another sense. It reminds us that we are appealing to a feature of our natures - a universal feature for us, albeit perhaps a contingent one. As structures in spacetime, we human agents all share a common temporal orientation. Imagine depicting our deliberative lives on a spacetime map, with a little arrow connecting each instance of deliberation to its associated action (where there is one). For us, all those little arrows point in the same direction from past to future, as we would normally put it.

Or, to go back to the turtles, think of yourself as a beach, and of your own plans and deliberations as the turtles that hatch on that beach. What's true is not only that all plans hatch in the same direction on each beach individually, but also that all the beaches we know of face in the same direction. It is an interesting question whether there could be creatures elsewhere whose beaches face in the other direction - whose plans hatch from future to past, by our lights. The answer is probably yes, in my view, so long as they are far enough away in spacetime to live in a region with low entropy in (what we call) the future, rather than (what we call) the past, but that's a long story. ${ }^{4}$ The point is that universality amongst us, individually and collectively, is quite enough to explain our sense that the direction of causation is an a priori matter - it is a priori, if you are built as we are, and if talk of causation depends on agency, in the sense that Ramsey suggests. (If Ramsey is right, then, the relevant contingency is not, as Russell thought, that memory only works backwards, but rather that deliberation only works forwards.)

\subsection{The past is off-limits ... or is it?}

In making agency central in this way, in spotting the special character of the agent's epistemic perspective, and in seeing the work it can do in giving us an account of the difference between cause and effect, I think Ramsey gets much further than Russell. But there's one respect in which Russell still outdoes him, in my view.

\footnotetext{
${ }^{4}$ See Price (1996) for an introduction to the issue.
} 
Ramsey actually gives us no reason at all why the epistemic bifurcation he identifies - the split between things for which our present volition can count as evidence, and things for which it can't - should line up neatly with the future/past distinction. $\mathrm{He}$ asserts confidently that it does, or at least that the entire past lies on the latter side of the line: "What is true is this, that any possible present volition of ours is (for us) irrelevant to any past event." But he offers no argument at this point, or explanation of the fact in question, if it is a fact. Russell at least has a punt at it, associating it with "the fact that the past but not the future can be known by memory."

This part of the puzzle wasn't properly sorted out until the 1960s, when the Oxford philosopher Michael Dummett pointed out (Dummett 1964) that one could quite coherently take oneself to affect the past - that is, in Ramsey's terms, take one's present volitions to be relevant to some past event - so long as one didn't take oneself to be able to know about the relevant part of the past, before one acted. ${ }^{5}$

Dummett points out that the knowledge condition might coherently be held to fail: there might be past events of which we thought that we couldn't have knowledge, at least at present, even in principle. If so, it isn't incoherent to think that we might affect them, by bring about some state of affairs in the future, with which they in turn are reliably correlated. Our initial action has to lie in the future, of course - that's the point above, about the turtles needing to swim East to get away from the beach. But in Dummett's picture our influence can then zig-zag back into the past, much as our turtles might then swim West, if gaps or inlets in the beach permitted it. In this respect then, I think that Ramsey misses something important. He's right about the character of the difference between cause and effect, but wrong about how it needs to line up with the distinction between past and future. Dummett shows how it might be false that, as Ramsey puts it, "any possible present volition of ours is (for us) irrelevant to any past event."

Dummett's own interest was in the efficacy of retrospective prayer, but I think his ideas have a more down-to-earth application, in the case of quantum mechanics - the reason we haven't noticed the gaps in the beach being that they so small, as it were. This is admittedly not a popular view, and I don't have time to explain it here, but I would like to put on record the view that the reason it has remained unpopular is in part because people who think about such things are unaware of the deep insight of Ramsey's view of causation, that it is the agent who is in the driver's seat, in determining the direction of causation in nature (in so far as there is such a thing), not the other way round. Or, if they are aware of it, they haven't also noticed what Ramsey got wrong and Dummett got right, that the resulting causal arrow need not point exclusively to the future. It may also be that Dummett's loophole is particularly hard to see, because our ordinary ways of causal thinking are so deeply ingrained - because they are hardwired, in effect. There has been much fascinating

\footnotetext{
${ }^{5}$ Interestingly, Dummett's discussion can be taken to show how the usual objections to backward causation rely on the same tension between knowledge and free action that lies at the heart of Ramsey's proposal - see Ahmed and Price (2012), §3, Price (2012).
} 
work in recent years by psychologists such as Alison Gopnik (e.g., Gopnik 2009), revealing the extent to which our causal thinking is innate (developing in various stages during infancy). If one were designing a folk physics for creatures like us, there's no doubt at all that simply treating the past as fixed - saying "Don't even think about affecting the past!" - would be a useful place to start. It's quick, and even if I'm right it's only dirty in places that are never going to matter, in ordinary life. (Similarly, turtles might be hardwired to swim East, even in an environment in which there were occasional opportunities to swim West.)

\subsection{Summary: what we get from Ramsey}

Setting aside this last issue, we can see that Ramsey offers us the beginnings of an answer to the two big puzzles about causation we identified earlier:

1. Field's challenge. Ramsey shows us how to reconcile Cartwright with Russell, without hyper-realism. Ramsey's Special Agent gives us the distinction Cartwright shows us that we need, between probabilistic dependencies encoded in the objective laws of association, and those that survive from the point of view of the deliberating agent.

2. The direction of causation. The difference between cause and effect is accounted for in terms of what we can manipulate to do what, and the prevailing temporal orientation of this 'causal arrow' is explained in terms of a contingent asymmetry in us, the fact that we deliberate "past-to-future". ${ }^{6}$

And the upshot is that Russell comes off rather well - if Ramsey is right, so too is Russell, about the claim that causation is not as fundamental as many philosophers have thought. More on this in a moment, but first a word about counterfactuals.

\section{A home for counterfactuals}

Where do counterfactuals fit in? A couple of pages earlier in 'General Propositions and Causality', Ramsey has this to say about the kind of conditional judgements we need in practical deliberation:

"When we deliberate about a possible action, we ask ourselves what will happen if we do this or that. If we give a definite answer of the form 'If I do $p, q$ will result,' this can properly be regarded as a material implication or disjunction 'Either not- $p$ or $q$ ' ' But it differs, of course, from any ordinary disjunction in that one of its members is not something of which we are trying to discover the truth, but something it is within our power to make true or false." (Ramsey 1929, p. 142, emphasis added)

\footnotetext{
${ }^{6}$ Itself traceable presumably to the thermodynamic asymmetry, though I haven't said anything about that here. See Price and Weslake (2009), Price (2007).
} 
Ramsey adds a footnote at this point: "It is possible to take one's future voluntary action as an intellectual problem: 'Shall I be able to keep it up?' But only by dissociating one's future self." (ibidem) What he is emphasising here is the special epistemic character of the agent's perspective, whose role a couple of pages later in the paper I described in $\S 3.2$ above.

Ramsey then continues:

"Besides definite answers 'If $p, q$ will result', we often get ones 'If $p, q$ might result' or ' $q$ would probably result'. Here the degree of probability is clearly not a degree of belief in 'Not- $p$ or $q$ ', but a degree of belief in $q$ given $p$, which it is evidently possible to have without a definite degree of belief in $p, p$ not being an intellectual problem. And our conduct is largely determined by these degrees of hypothetical belief." (ibidem, emphasis added)

In other words, Ramsey is claiming here that the kind of conditionals we need in deliberation are not counterfactuals, not claims about what would be the case had something been different. They are hypotheticals, claims about what is true if something is the case, for a very special kind of "something" - propositions that can't be intellectual problems, as he puts it, because we take them to be "within our power to make true or false."

If Ramsey is right, then we don't need counterfactuals, where many people have thought that we do need them, as a foundation for our theory of decision. Instead we have the prospect that we might be able to explain talk of counterfactuals in terms of these simpler kind of hypotheticals. Something like this idea has been proposed by the psychologist Alison Gopnik, I think (see, e.g., Gopnik 2009). Her idea is that we can employ these deliberative skills not merely online, when facing real choices, but also offline, when facing imaginary choices (or, perhaps a better way to put it, when imagining that we are facing real choices). "Counterfactuals are the price we pay for hypotheticals," as Gopnik puts it: they are a kind of byproduct of the hypotheticals we need in decision, combined with our faculty of imagination. Again, I don't have time to explore this idea here. The point I want to make is simply that if it is correct, then it will give us a satisfyingly Russellian account of counterfactuals, just as Ramsey's main proposal does for causation.

\section{Causal republicanism}

So are there causes, if Ramsey is right? I think the answer is, "Yes, but they're not as much part of the furniture as we might have thought." Causation goes on the side of the secondary qualities, to use an analogy I explored in an early paper with Peter Menzies (Menzies and Price 1993). As Richard Corry and I noted in a recent collection (Price and Corry 2007), we can characterise this option in terms of Russell's own constitutional metaphor. In the political case, we can distinguish three views of political authority. A traditional monarchist, at one extreme, takes 
it to be vested in our rulers by God. If we reject that view, we have two choices: the anarchist option of rejecting the notion of political authority altogether; or the milder republican option, which agrees with the traditional monarchist that there is political authority, but sees it as a social creation, vested in our rulers by us.

By analogy, the republican option exists in metaphysics, too. Causal republicanism is thus the view that although the notion of causation is useful, perhaps indispensable, in our dealings with the world, it is a category provided neither by God nor by physics, but rather constructed by us. From this republican standpoint, then, thinking of eliminativism about causality as the sole alternative to full-blown realism is like thinking of anarchy as the sole alternative to the divine right of kings.

As I noted, there's an issue about where we put Russell: Is he an anarchist or a republican, in this new terminology? I suggested that we might see him, with Hume, as what now counts as an armchair anarchist, happy to retain talk of causation and counterfactuals for ordinary purposes. And that's really the republican option, or at least the reflective, clear-headed version of the republican option, that wants to combine a full-blooded participation in ordinary ways of speaking with a detached, over-the-shoulder understanding of how we come to speak that way, and how it might have been otherwise - "contingency, irony and solidarity," in the words of another of my philosophical heroes.

How is this news going to be taken by the market? It won't be a shock, presumably, to learn that market values reflect the subjective preferences we humans have for various possible ends and outcomes. (Another of Ramsey's great contributions was to figure out how to systematise and measure such things, along with our degrees of belief, in the context of their role in guiding our choices.) All of this depends on the fact that we are creatures who operate under uncertainty: "All our lives we are in a sense betting," as Ramsey puts it (1926, p. 85). What the republican view of causation does is to extend the story to the case of creatures who are also agents - they intervene in the environment about which they hold such beliefs and preferences. Certainly it shows that causal and counterfactual talk would be unneeded for creatures who didn't do that - intelligent trees, for example, as Michael Dummett (1964, p. 339) once put it. But that's no threat to the real estate market, obviously, unless the good folk of Manhattan become a lot more passive than they have tended to be to date.

\section{Russell and the monarchy}

So much for causation. But when it occurred to me that I had an opportunity to celebrate the centenary of "On the Notion of Cause" on this occasion, I was curious about what Russell had had in mind in the other part of his famous line: just what, in Russell's view, is the harm that the monarchy is erroneously thought not to do? I assumed that this would be an easy curiosity to satisfy - somewhere, presumably, Russell would have expressed his views about the monarchy at greater length. But I searched in vain. 
Eventually I wrote to Nicholas Griffin, of the Russell Archives at McMaster. He told me that there was really nothing to find, not even in Russell's correspondence, so far as he knew it. But he did suggest a context for Russell's remark. In 1910 Britain had concluded a considerable constitutional crisis, bought on by the Liberal government's determination to remove the veto power of the House of Lords. A crucial step had been the King's indication that he would support the government, if necessary, by creating a sufficient number of new Liberal peers to ensure passage of the Bill through the Lords. (Russell himself would have been one of those new peers, apparently, in that counterfactual world.) Professor Griffin suggested that in the light of the King's support, some on the Liberal side of politics were inclined to say that the monarchy wasn't so bad after all; and that Russell may have been taking the opportunity to indicate that he was made of sterner stuff - that the old battle lines of the Russells remained unchanged, as it were.

But that doesn't tell us what Russell thought that the harm in question actually was, at that point in the nation's history - when, thanks in part to Russell's own ancestors, it had long been a "crowned republic", as Tennyson put it (a fact reaffirmed and strengthened in the recent crisis, of course). So, as my centenary footnote to Russell's great paper, I want to finish by giving you my own view. In my view, there is a significant cost to modern constitutional monarchies that is remarkable, among other things, for the fact that although it is in plain sight, it goes unmentioned, and apparently almost unnoticed. As you'll see, it is indeed a relic of a bygone age, whose significance is hidden from us by the sheer familiarity of the system of which it is a consequence - by the fact that a traditional picture holds us in its grip, as Wittgenstein might have put it. Moreover, while I'm not suggesting that this is what Russell actually had in mind, it is, as you'll also see, something that he in particular would have had reason to have in mind - it resonates in several ways with significant aspects of his own life. And it connects in a deep way with the themes I have been talking about so far. In all senses, then, it's an excellent fit.

I can introduce the point by noting a difference of opinion with most of my Australian compatriots. A majority of Australians appear to favour an Australian republic, even though many of them voted against it when they had the chance some years ago, because they didn't like the model on offer. But the main reason given is that Australia should have an Australian head of state, rather than the British monarch - and while I don't disagree with that sentiment, I do think it misses a much more powerful appeal to the country's professed values.

Australia's next head of state, under present arrangements, is a man whose affection for the country dates from 1966, when he was sent for a couple of terms to a boarding school there. It was a formative experience, apparently - "If you want to develop character, go to Australia" (Wales 2011), as he put it recently (going on to mention some of the character-building epithets employed by his Australian schoolmates). I feel very much on the same wavelength as the Prince at this point, because I encountered those same character-building opportunities, and no doubt the same epithets, the very same year, as a teenage migrant from the UK - I arrived just three weeks after he left. 
Our lives diverged quite markedly after that point, of course. He came to Cambridge, had a memorable gig in Wales in 1969, and has now served his country and the Commonwealth with considerable distinction, for more than forty years. I went to ANU, making the first of many choices that turned out to lead, happily and rather surprisingly, to the present occasion. (Not quite a gig in Wales, perhaps, but memorable for me, nonetheless!)

But the particular difference I want to highlight is that in common with most of my generation, in countries such as Britain and Australia, I made choices about what to do with my life; whereas he did not, to an unusual extent. Significant as his life's work is, my famous contemporary did not have the opportunity to choose it, or to volunteer for it, in any meaningful sense.

So that's why I disagree with most of my compatriots, republicans and monarchists alike, about the issue of an Australian republic. They think that the question turns on the importance or otherwise of Australia's having an Australian head of state. I think that that's a trivial matter, a mere sideshow, compared to the principle that all young people should be allowed to choose for themselves what they do with their lives, when they grow up. The professed Australian value I mentioned a moment ago is simply that of fairness - of a "fair go," as Australians say. It seems to me profoundly and manifestly unfair to select children by accident of birth for future public office - especially so, of course, for such an important, symbolic and public public office - and hence entirely inappropriate that Australia's constitution should make us party to a practice of doing so.

Apart from the fact that Australians like to make a fuss about fairness, there's nothing uniquely Australian about the point, of course. It applies with equal force in all the modern democratic monarchies - almost all of which (eight in total, neglecting some tiny principalities) are in Europe. The eight countries in question three Scandinavian countries, three Benelux countries, Spain, and Britain - actually care just as much about fairness as Australians do, of course. So it's an issue for all of them, in just the same way.

It is easy to see why I think this point is Russellian in spirit. As is well known, Russell felt the constraints of his own childhood very deeply, and was greatly relieved to escape them when he came of age. ${ }^{7}$ Later, when he himself became a father, Russell was a famous advocate of allowing children as much freedom as possible. And finally, of course, he was also a famous opponent of conscription.

It would be a little extreme, perhaps, to compare hereditary monarchy to conscription. A neutral term might be "involuntary service", or "involuntary servitude", as prohibited by the landmark Thirteenth Amendment to the US Constitution. In that case, the US Supreme Court later ruled that the Amendment did not prohibit service properly rendered to the state, such as military conscription, or jury duty. But as those cases make clear, it would be unthinkable that these exclusions

\footnotetext{
${ }^{7}$ The heirs to the monarchies of Europe don't have that opportunity, of course. It is true that in principle they could abdicate, but at considerable cost - like it or not, they are public figures, after all - and only by passing the unasked-for obligation to a sibling or cousin.
} 
might be lifetime matters (or apply to individuals chosen in infancy, presumably).

It would be unthinkable in any other advanced democracy, too, if we were starting from scratch. If someone proposed that we should fill public offices by selecting infants who would be brought up to fill the roles in question, the main objection would not be that it was undemocratic, but that it was absurdly unfair to the individuals concerned. The fact that we do find this system thinkable in practice turns mainly on its sheer familiarity - that's just how things are done. And perhaps, as Russell thinks in the case of causation, we are still in the grip of a piece of bad metaphysics: we think of royalty as a natural kind, and hence imagine that it is a natural matter that royal children should be brought up to play these roles - that's the kind of beings they are, as it were. The picture holds us captive, and central to it is the fantasy that what these families enjoy is a matter of entitlement and privilege, not constraint and obligation.

It is easy to see how we got to this point, from the distant past this picture actually depicts: on the one hand, a great erosion of power on the side of royalty, as - thanks in part to Russell's ancestors, in the British case - its powers were curtailed; on the other hand, an even greater expansion of opportunity on the side of ordinary people, especially ordinary children, as we have come to accept that young people should make their life choices for themselves, rather than have them dictated by parents or accidents of birth. The combination of these two factors means that the heirs to modern monarchies are now marooned on a little island of underprivilege: impoverished not only compared to their own ancestors, but also, much more importantly, by the standards that now exist in the community at large.

\subsection{Counterfactual deprivation}

Here the point connects back to the main themes of my lecture, and indeed of Russell's, broadly interpreted. For what precisely is it that these individuals lack, compared to their contemporaries? Of what are they deprived? Essentially, it is counterfactuals. They are deprived of counterfactuals, of opportunities to make decisions about their lives on the large scale, in much the same way that New Jersey is deprived compared to Manhattan, about admittedly more trivial matters, to return to Fodor's observation about the real estate market.

So the two sides of Russell's famous metaphor come together. The reason we need to be at most armchair anarchists about causation and counterfactuals, turns, in part, on the role these notions play in human life, and particularly our conception of a rich human life, a life with choices, a life with counterfactuals. It would be unthinkable, probably impossible, to live life without them, even if they are not fundamental, and have no role in fundamental physics, suitably construed. And the great flaw of modern hereditary monarchies lies in the way in which they deprive a few individuals of some of these freedoms. This flaw has precisely the character suggested by Russell's comparison: a significant harm, in plain sight, to which we are blinded by familiarity and bad metaphysics. 


\section{Conclusion}

With some renovation, then - new foundations provided by Ramsey on the side of causation, and a sympathetic addition of the wing that Russell himself did not construct, on the side of the monarchy - Russell's edifice thus turns out to be in remarkably good shape, on the eve of its one hundredth birthday. Please join me in wishing it well.

\section{References}

Ahmed, A. and Price, H. (2012) “Arntzenius on 'Why Ain'cha Rich?”, Erkenntnis 77: $15-30$.

Anscombe, G. E. M. (1971) Causality and Determination. Cambridge: Cambridge University Press. Reprinted in her Metaphysics and the Philosophy of Mind (The Collected Philosophical Papers of G. E. M. Anscombe, Volume 2), Minneapolis, MN: University of Minnesota Press, 1981, pp. 133-47. Page references are to the latter version.

Cartwright, N. (1979) "Causal Laws and Effective Strategies”, Noûs 13: 419-37.

Collingwood, G. (1940) An Essay in Metaphysics. Oxford: Oxford University Press.

Dummett, M. A. E. (1954) "Can an Effect Precede its Cause?", Proceedings of the Aristotelian Society Supplementary Volume 38: 27-44.

Dummett, M. A. E. (1964) "Bringing about the Past", Philosophical Review 73: 338-59.

Field, H. (2003) "Causation in a Physical World", in: M. Loux and D. Zimmerman, eds. Oxford Handbook of Metaphysics. Oxford: Oxford University Press, pp. 43560.

Gasking, D. (1955) "Causation and Recipes", Mind 64: 479-87.

Gopnik, A. (2009) The Philosophical Baby: What Children's Minds Tell Us about Truth, Love, and the Meaning of Life. New York: Farrar, Straus and Giroux.

Lewis, D. (1979) “Counterfactual Dependence and Time's Arrow”, Noûs 13: 45576.

Mellor, D. H. (1988) The Warrant of Induction. Cambridge: Cambridge University Press. Reprinted in his Matters of Metaphysics, Cambridge: Cambridge University Press, 1991, pp. 254-68. Page references here are to the latter version.

Menzies, P. and Price, H. (1993) "Causation as a Secondary Quality", British Journal for the Philosophy of Science 44, 187-203.

Pearl, J. (2000) Causality. New York: Cambridge University Press.

Price, H. (1991) "Agency and Probabilistic Causality", British Journal for the Philosophy of Science 42: 157-76. 
Price, H. (1996) Time's Arrow and Archimedes' Point: New Directions for the Physics of Time, New york: Oxford University Press.

Price, H. (1993) “The Direction of Causation: Ramsey's Ultimate Contingency”, in: D. Hull, M. Forbes and K. Okruhlik, eds. PSA 1992, Volume 2. East Lansing, Michigan: Philosophy of Science Association, pp. 253-67.

Price, H. (2007) "Causal Perspectivalism", in: H. Price and R. Corry, eds. (2007) Causation, Physics, and the Constitution of Reality: Russell's Republic Revisited. Oxford: Oxford University Press, pp. 250-92.

Price, H. (2012) "Causation, Chance and the Rational Significance of Supernatural Evidence", Philosophical Review 121: 483-538.

Price, H. and Corry, R, eds. (2007) Causation, Physics, and the Constitution of Reality: Russell's Republic Revisited. Oxford: Oxford University Press.

Price, H. and Weslake, B. (2009) "The Time-Asymmetry of Causation", in: H. Beebee, C. Hitchcock and P. Menzies, eds. The Oxford Handbook of Causation. Oxford: Oxford University Press, pp. 414-43.

Rabinowicz, W. (2002) “Does Practical Deliberation Crowd Out Self-prediction?", Erkenntnis 57: 91-122.

Ramsey, F. P. (1926) "Truth and Probability”, in: D. H. Mellor, ed. Foundations: Essays in Philosophy, Logic, Mathematics and Economics. London: Routledge and Kegan Paul, 1978, pp. 58-100.

Ramsey, F. P. (1929) "General Propositions and Causality”, in: D. H. Mellor, ed. Foundations: Essays in Philosophy, Logic, Mathematics and Economics. London: Routledge and Kegan Paul, 1978, pp. 133-51.

Russell, B. (1913) "On the Notion of Cause," Proceedings of the Aristotelian Society, New Series 13, 1-26.

Suppes, P. (1970) A Probabilistic Theory of Causality. Amsterdam: North-Holland. von Wright, G. (1975) Causality and Determinism. New York: Columbia University Press.

Wales, C. (2011) Personal remarks cited in: “'Pommy Bastard' Prince Charles Reveals 'Huge Affection' for Australia”, The Age, 27 January 2011, online at http://www.theage.com.au/world/pommy-bastard-prince-charles-reveals-huge-affectionfor-australia-20110127-1a5na.html (accessed 8 April 2013).

Woodward, J. 2003. Making Things Happen: A Theory of Causal Explanation. Oxford: Oxford University Press. 